\title{
Interrelations between three proxies of health care need at the small area level: an urban/rural comparison
}

\author{
S Barnett, P Roderick, D Martin, I Diamond, H Wrigley
}

J Epidemiol Community Health 2002;56:754-761

\begin{abstract}
Study objective: To examine the relations between geographical variations in mortality, morbidity, and deprivation at the small area level in the south west of England and to assess whether these relations vary between urban and rural areas.

Design: A geographically based cross sectional study using 1991 census data on premature limiting long term illness (LLTI) and socioeconomic characteristics, and 1991-1996 data on all cause premature mortality. The interrelations between the three widely used proxies of health care need are examined using correlation coefficients and scatterplots. The distribution of standardised LLTI residuals from a regression analysis on mortality are mapped and compared with the distribution of urban and rural areas. Multilevel Poisson modelling investigates whether customised deprivation profiles improve upon a generic deprivation index in explaining the spatial variation in morbidity and mortality after controlling for age and sex. These relations are examined separately for urban, fringe, and rural areas.

Setting: Nine counties in the south west of England.

Participants: Those aged between 0-64 who reported having a LLTI in the 1991 census, and those who died during 1991-1996 aged 0-74.

Main results: Relations between both health outcomes and generic deprivation indices are stronger in urban than rural areas. The replacement of generic with customised indices is an improvement in all area types, especially for LLTI in rural areas. The relation between mortality and morbidity is stronger in urban than rural areas, with levels of LLTI appearing to be greater in rural areas than would be predicted from mortality rates. Despite the weak direct relations between mortality and morbidity, there are strong relations between the customised deprivation indices computed to predict these outcomes in all area types.

Conclusions: The improvement of the customised deprivation indices over the generic indices, and the

similarity between the mortality and morbidity customised indices within area types highlights the importance of modelling urban and rural areas separately. Stronger relations between mortality and morbidity have been revealed at the local authority level in previous research providing empirical evidence that the inadequacy of mortality as a proxy for morbidity becomes more marked at lower levels of aggregation, especially in rural areas. Higher levels of LLTI than expected in rural areas may reflect different perceptions or differing patterns of illness. The stronger relations between the three proxies in urban than rural areas suggests that the choice of indicator will have less impact in urban than rural areas and strengthens the argument to develop better measures of health care need in rural areas.
\end{abstract}

See end of article for authors' affiliations

Correspondence to:

Dr P Roderick, Health Care Research Unit, University of

Southampton, Southampton

General Hospital,

Southampton SO 16 6YD,

UK; pir@soton.ac.uk

Accepted for publication

18 January 2002

t is difficult to measure "health care need" and therefore to create formulas that provide an equitable solution to the allocation of health care resources. Standardised mortality ratios (SMRs) have long been used as proxy measures for morbidity in resource allocation formulae. ${ }^{1}$ They were originally introduced on the grounds that no routine and reliable measures of morbidity existed that were independent of the supply of services. The RAWP report for the National Health Service in 1976 concluded that the reasons for the patterns of differential mortality were not wholly understood but that differences in morbidity explained the greater part of it, and that statistics of relative differences in morbidity, if they existed, would exhibit the same pattern as those for mortality. ${ }^{1}$ Mortality data can only provide a proxy for health rather than measure it directly, and there has been considerable debate about the limitations of the measure. ${ }^{2-6}$ It has also been suggested that the inadequacy of the SMR as an indicator of morbidity would become more marked for lower levels of aggregation because of the smaller number of deaths involved, ${ }^{3}$ although to date this suggestion has not been explored.

The introduction of a question on limiting long term illness (LLTI) in the 1991 UK census provided for the first time information on perceived levels of morbidity at the small area level.
It should produce a more reliable measure of health care need among younger age groups than mortality as it includes conditions that are not life threatening, but that none the less place demands on health services. Initial analysis of the 1991 census suggested that LLTI data were reasonably accurate and within a short period LLTI was recommended as a key needs indicator for resource allocation purposes, ${ }^{7}$ and it has been adopted as such by the Department of Health. ${ }^{8}$

Demographic data have been used to explore health care need but marked social and geographical variation in health status remains after controlling for these. Variations in mortality have been shown to be strongly associated with social deprivation. ${ }^{9}$ Therefore deprivation indices have been developed and are often used as proxies for health care need in health needs assessment, health service planning, health research and resource allocation. ${ }^{6 \mathrm{a}-12}$ However, our previous papers have illustrated that generic deprivation indices are urban biased (for example, car ownership has different meanings and implications in urban and rural areas), and that

Abbreviations: LLTI, limiting long term illness; SMR, standardised mortality ratio; $E D$, enumeration district 

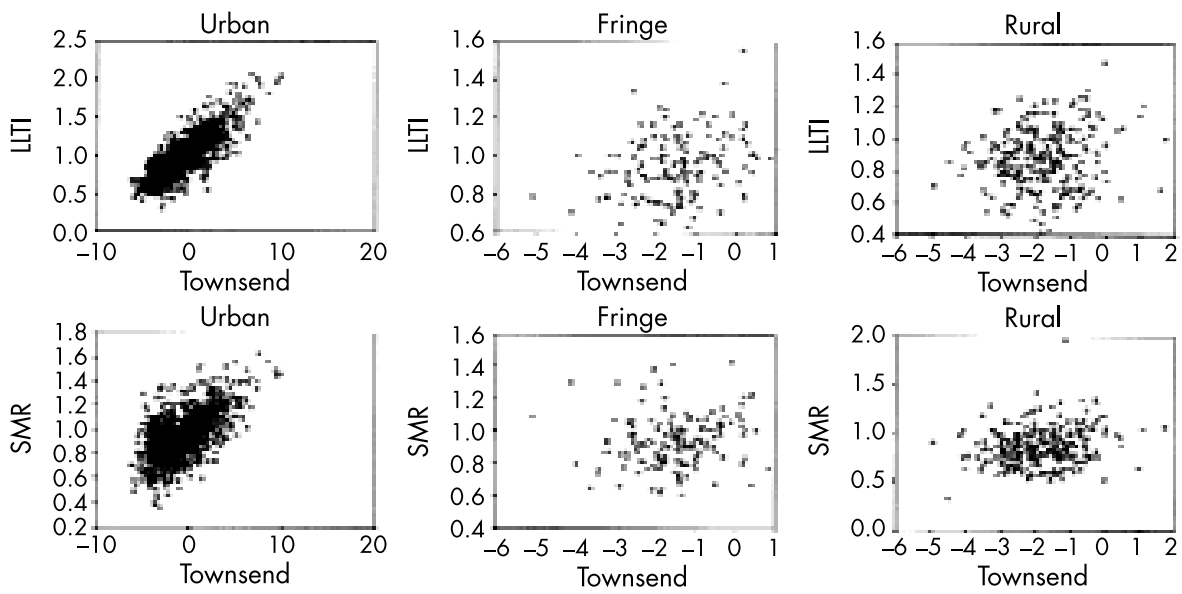

Figure 1 Scatterplots showing the relation between the standardised health outcomes and the Townsend deprivation index at ward level by area type.

customised indices can be a marked improvement at explaining the variation in health status in rural areas. ${ }^{13}{ }^{14}$ Furthermore, socioeconomic measures have been found to be associated with some measures of morbidity but not others. ${ }^{15}$ This suggests that when allocating health care resources it may not be adequate only to focus upon the demographic and socioeconomic characteristics of a population, but also to attempt to assess their relative health status.

There is a need for indices that measure or represent health care need and to allocate health care resources at the small area level in urban and rural areas. Measures of deprivation, mortality, and morbidity are commonly used for these purposes, although the combinations of these indicators do vary. This paper aims to examine the interrelations between these variables at the small area level and to explore whether these relations vary between the different area types, in particular making urban-rural comparisons. The paper builds on previous work, which compared the relation between LLTI and deprivation in different area types, ${ }^{13}$ by examining whether the relation with deprivation varies for mortality. The relation between the 1991 census LLTI question and mortality has previously been examined at the local authority level ${ }^{* 16}{ }^{17}$ this paper explores this relation at the small area level and examines whether the relation varies between urban and rural areas.

\section{METHODS}

\section{Data}

The analyses in this paper concentrate on the nine counties in the South West Region in 1991: Avon, Cornwall and the Isles of Scilly, Devon, Dorset, Gloucestershire, Hampshire, Isle of Wight, Somerset, and Wiltshire. Together, these comprise a population of just over six million.

All of the analyses carried out in this paper are performed separately for different area types to allow for any areal differences. The groupings are based on the Office for National Statistics (ONS) Ward Classification that classifies all of the census wardst in England and Wales into one of 14 groups. Two of these groups are Rural Fringe and Rural Areas, which are kept separate throughout this paper and termed "fringe" and "rural" respectively. The remaining 12 groups are aggregated to form the urban group termed "urban". The average population sizes were in urban wards median 3327 (IQR 1843-5378), in rural fringe wards median 2460 (IQR 1684-3851), and in rural areas median 3327 (IQR 1843-5318).

${ }^{*}$ A local authority district typically contains about 600 enumeration districts.
The indicators of deprivation are derived from the 1991 census data. The Small Area Statistics (SAS) provide the input for the calculation of the widely used Townsend deprivation index ${ }^{11}$ at the enumeration district (ED) $\ddagger$ and ward levels, which is used as an example of a generic deprivation index throughout. The Townsend deprivation index tends to be one of the best and most widely used indices currently available, adhering most closely to the concept of material disadvantage. ${ }^{18}$ The SAS also provide the components of three other widely used deprivation indices at the ED and ward levels: Carstairs, ${ }^{6}$ Jarman UPA, ${ }^{10}$ and the Department of the Environment. ${ }^{11}$ In this paper we use the standardised components of each of the four widely used indices to compute six health based customised deprivation indices, for both mortality and morbidity in urban, fringe, and rural areas.

The morbidity data are derived from the LLTI question in the 1991 census. The SAS provide the data on the number of people resident in households, under the age of 65 , who reported an LLTI in the census. The data exclude those living in communal establishments. The median number of people aged 0-64 reporting a LLTI in 1991was 192 (IQR 101 to 326) in urban wards, 153 (IQR 104 to 225) in rural fringe wards, and 77 (IQR 60 to 98 ) in rural wards.

The average rate of LLTI per thousand was 59 (IQR 48 to 72 SE 4.15) in urban areas, 60 (IQR 53 to 68, SE 4.65) in rural fringe areas, and 60 (IQR 50 to 69 SE 6.57) in rural areas.

The mortality data were obtained from the ONS for the number of deaths from all causes to those in the $0-74$ age group. Deaths occurring in the period 1991-96 are grouped and also the age range is larger than for LLTI to try to mitigate the small number problem and to reduce the risk of data from just one year being unrepresentative. The median number of deaths in age group 0-64 in the six year period was 98 (IQR 56,161 ) in urban areas, 82 (IQR 52 to 122) in rural fringe areas, and 41 (IQR33 to 51 ) in rural areas. The average annual mortality rate per 1000 was 2.16 (IQR 1.78 to 2.58 , SE 0.33 ) in urban areas, 2.16 (IQR 1.87 to 2.48 SE 0.37 ) in rural fringe areas and 2.22 (IQR 1.78 to $2.74 \mathrm{SE} 0.52$ ) in rural areas. The mortality data were postcoded and are therefore assigned to EDs and wards using the national postcode to enumeration district directories held at Manchester Information and Associated Services (MIMAS).

†A census ward typically contains about 13 enumeration districts. $\ddagger$ An enumeration district has on average about 200 households. It is the area covered by a single enumerator in the decennial census. 
Table 1 Fitted models $†$ for LLTI comparing deprivation measures

\begin{tabular}{|c|c|c|c|c|c|c|c|c|c|c|c|c|c|}
\hline & & \multicolumn{6}{|c|}{ Generic deprivation index models } & \multicolumn{6}{|c|}{ Customised deprivation index models } \\
\hline & & \multicolumn{2}{|l|}{ Urban } & \multicolumn{2}{|l|}{ Fringe } & \multicolumn{2}{|l|}{ Rural } & \multicolumn{2}{|l|}{ Urban } & \multicolumn{2}{|l|}{ Fringe } & \multicolumn{2}{|l|}{ Rural } \\
\hline & & $\beta$ & RR & $\beta$ & $\mathrm{RR}$ & $\beta$ & $\mathrm{RR}$ & $\beta$ & RR & $\beta$ & RR & $\beta$ & RR \\
\hline \multicolumn{2}{|c|}{ Constant } & \multicolumn{2}{|l|}{-3.77} & \multicolumn{2}{|l|}{-3.75} & -3.99 & - & -3.75 & - & -3.68 & - & -3.80 & - \\
\hline Sex: & $\begin{array}{l}\text { Male } \\
\text { Female }\end{array}$ & \multicolumn{2}{|l|}{$\begin{array}{l}0.00 \\
-0.23^{*}\end{array}$} & \multicolumn{2}{|l|}{$\begin{array}{l}0.00 \\
-0.21^{*}\end{array}$} & $\begin{array}{l}0.00 \\
-0.18^{*}\end{array}$ & $\begin{array}{l}1.00 \\
0.83\end{array}$ & \multicolumn{2}{|l|}{$\begin{array}{l}0.00 \\
-0.23^{*}\end{array}$} & \multicolumn{2}{|l|}{$\begin{array}{l}0.00 \\
-0.21 \text { * }\end{array}$} & $\begin{array}{l}0.00 \\
-0.18^{*}\end{array}$ & $\begin{array}{l}1.00 \\
0.83\end{array}$ \\
\hline Age: & $\begin{array}{l}0-15 \\
16-44 \\
45-54\end{array}$ & $\begin{array}{l}0.00 \\
0.62^{*} \\
1.87^{*}\end{array}$ & & $\begin{array}{l}0.00 \\
0.61^{*} \\
1.88^{*}\end{array}$ & & $\begin{array}{l}0.00 \\
0.74^{*} \\
1.91^{*}\end{array}$ & $\begin{array}{l}1.00 \\
2.10 \\
6.75\end{array}$ & $\begin{array}{l}0.00 \\
0.62^{*} \\
1.87^{*}\end{array}$ & & $\begin{array}{l}0.00 \\
0.61^{*} \\
1.87^{*}\end{array}$ & & $\begin{array}{l}0.00 \\
0.74^{*} \\
1.99 *\end{array}$ & $\begin{array}{l}1.00 \\
2.10 \\
6.74\end{array}$ \\
\hline \multicolumn{2}{|c|}{$\begin{array}{l}\text { Females * age } 16-44 \\
\text { Females * age } 45-64\end{array}$} & \multicolumn{2}{|l|}{$0.13^{*}$} & \multicolumn{2}{|l|}{$0.13^{*}$} & & & \multicolumn{2}{|l|}{$0.13^{*}$} & \multicolumn{2}{|l|}{$0.13^{*}$} & & \\
\hline ED Tov & vnsend deprivation index & $0.10^{*}$ & 1.10 & $0.09 *$ & 1.09 & $0.06^{*}$ & 1.06 & & & & & & \\
\hline ED sta & ndardised deprivation indicators: & & & & & & & & & & & & \\
\hline Une & mployment & & & & & & & $0.72 *$ & 2.21 & $0.15^{*}$ & 1.16 & $0.04^{*}$ & 1.04 \\
\hline No & car ownership & & & & & & & $0.27^{*}$ & 1.31 & $0.19 *$ & 1.21 & $0.27^{*}$ & 1.31 \\
\hline Lack & of basic amenities & & & & & & & $0.20 *$ & 1.22 & $0.26^{*}$ & 1.30 & $0.28^{*}$ & 1.33 \\
\hline Rece & ent migrant & & & & & & & & & $-0.04^{*}$ & 0.96 & & \\
\hline Ove & rcrowding & & & & & & & $0.05^{*}$ & 1.06 & & & & \\
\hline Low & social class & & & & & & & $0.03^{*}$ & 1.03 & & & & \\
\hline Unsk & killed & & & & & & & $0.01 *$ & 1.01 & & & $0.02 *$ & 1.02 \\
\hline Chil & dren in low earning households & & & & & & & & & $0.98^{*}$ & 2.65 & $0.97^{*}$ & 2.64 \\
\hline Not & owner occupier & & & & & & & & & $0.05^{*}$ & 1.05 & & \\
\hline Sing & le parent households & & & & & & & $0.04^{*}$ & 1.04 & & & & \\
\hline ED lev & el variance (SE) & 0.0281 & $(0.001)$ & 0.02310 & $0.003)$ & 0.02810 & $0.004)$ & 0.025 & $(0.001)$ & 0.01810 & $0.003)$ & 0.02110 & (0.004) \\
\hline Ward & level variance (SE) & 0.0121 & $(0.001)$ & 0.01110 & $0.002)$ & 0.00610 & $0.002)$ & 0.010 & $(0.001)$ & 0.00910 & 0.002) & 0.00510 & $0.002)$ \\
\hline DHA le & evel variance (SE) & 0.008 & $(0.003)$ & 0.00610 & $0.004)$ & 0.02010 & $0.010)$ & 0.006 & (0.003) & 0.00510 & $0.003)$ & 0.01810 & $0.009)$ \\
\hline $\begin{array}{l}\text { Wald } \\
\text { depriv }\end{array}$ & $\begin{array}{l}\chi^{2} \text { (change in df for addition of } \\
\text { ation) }\end{array}$ & 7602.3 & 39 (1 df) & 426.49 & (ldf) & 85.28 & $1 \mathrm{df})$ & 8647.8 & 35 (7df) & 579.12 & (6df) & 211.87 & $(5 \mathrm{df})$ \\
\hline
\end{tabular}

\section{Design}

The relation between the health outcomes and deprivation is explored using scatterplots and correlation coefficients of the geographical distribution of the Townsend deprivation index and age and sex standardised mortality and morbidity ratios at the ward level.

Multilevel modelling is used to explore the impact of deprivation in explaining the spatial variation in the health outcomes once age and sex have been controlled for. Initially the Townsend index is used and subsequently this is replaced with customised deprivation profiles to allow comparisons to be made.

The most appropriate statistical model for rare events at the small area level is the Poisson model. ${ }^{19}$ As a hierarchy exists in the dataset a multilevel methodology is used to permit variables at different levels of aggregation to be analysed simultaneously, ${ }^{20}$ using the MLwiN software package. ${ }^{21}$ Individual level data are not available from SAS. Therefore, at the lowest level of the hierachy (level 1) age/sex groups are considered. They are nested within EDs (level 2), wards (level 3 ), and district health authorities (level 4). Models are fitted to account for the variation in the number of people with the health outcome in each age-sex group in an ED by the potential explanatory factors in the different levels of data structure. The expected number of people in an age-sex group with the health outcome is written as $\mathrm{N}_{\mathrm{ijk} \mid} \lambda_{\mathrm{ijk} \mid \mathrm{l}}$. A Poisson distribution is assumed for the observed counts $Y_{\mathrm{ijkl}}$ with mean $\mathrm{N}_{\mathrm{ijk},} \lambda_{\mathrm{ijkl} .}$

The model can be written in standard log linear form as:

$$
\begin{aligned}
\log _{\mathrm{e}}\left(\mathrm{N}_{\mathrm{ijkl}} \lambda_{\mathrm{ijkl}}\right)=\log _{\mathrm{e}}\left(\mathrm{N}_{\mathrm{ijkl}}\right) & +\alpha+\beta \mathbf{X}^{\mathrm{T}}{ }_{\mathrm{ijkl}}+\mathrm{F}_{1} \\
& +\mathrm{V}_{\mathrm{kl}}+\mathrm{U}_{\mathrm{jkl}}+\varepsilon_{\mathrm{ijkl}}
\end{aligned}
$$

where:

$\mathrm{N}_{\mathrm{i} \mathrm{jk} \mathrm{l}}=$ the enumeration district population in age-sex group $i$ in $\mathrm{ED} j$ in ward $k$ in DHA $l$

$\lambda_{\mathrm{ijk}}=$ the expected number of people with LLTI or died

$\alpha_{-}=$constant

$\beta=$ the vector of parameters of interest

$\mathbf{X}_{\mathrm{i} \mathrm{jk} \mathrm{l}}=$ the vector of covariates

$\mathrm{F}_{1}=$ DHA residual term, distributed $\mathrm{N}\left(0, \sigma_{\mathrm{f}}^{2}\right)$

$\mathrm{V}_{\mathrm{kl}}=$ Ward residual term, distributed $\mathrm{N}\left(0, \sigma_{\mathrm{v}}^{2}\right)$

$\mathrm{U}_{\mathrm{jkl}}=$ ED residual term, distributed $\mathrm{N}\left(0, \sigma_{\mathrm{u}}^{2}\right)$

The term $\log _{\mathrm{e}}\left(\mathrm{N}_{\mathrm{ijk}}\right)$ is a (fixed) known offset. Offsetting is a common procedure to transform a standard Poisson model into a $\log$ rates model. ${ }^{20}$ To avoid multicollinearity ${ }^{23}$ no two variables with a correlation of greater than 0.6 are incorporated into the same model. Model selection is by a combination of forwards and backwards selection using the second order PQL estimation procedure. This is used to improve the accuracy of the estimates. ${ }^{25}$ The standardised deprivation components of each of the four generic deprivation indices are tested singularly with the aim of identifying the best additive effect. The components are kept separate in the models rather than aggregating them to form a new index, thus allowing the model to determine a set of weights for each significant indicator of deprivation from the regression coefficients. Subsequently, these weights are used to compute mortality and morbidity customised deprivation indices. These are defined as follows:

Customised deprivation index $=\Sigma\left(\beta_{1} X_{1 k}+\beta_{2} X_{2 k}+\ldots+\right.$ $\beta p \mathrm{Xp}_{\mathrm{k}}$ ) 
Table 2 Relative risks of LLTI by age and sex for the urban and fringe models

\begin{tabular}{llllll}
\hline & \multicolumn{3}{c}{ Urban } & & \multicolumn{2}{l}{ Fringe } \\
\cline { 2 - 3 } \cline { 5 - 5 } & Males & Females & & Males & Females \\
\hline $0-15$ & 1.00 & 0.80 & 1.00 & 0.81 \\
$16-44$ & 1.85 & 1.68 & 1.84 & 1.69 \\
$45-64$ & 6.48 & 5.70 & 6.52 & 5.61 \\
\hline
\end{tabular}

where:

$\beta 1$. . $\beta p$ are coefficients estimated in the multilevel regression modelling

$\mathrm{X} 1 \ldots \mathrm{Xp}$ are deprivation indicators

$\mathrm{p}=$ Number of deprivation indicators

$\mathrm{k}=$ Electoral Ward

The relations between the geographical distribution of mortality and morbidity are explored using scatterplots and correlation coefficients. Maps are used to compare the standardised LLTI residuals from a simple regression analysis on mortality with a map of the urban, rural, and fringe areas. The components of the mortality and morbidity customised deprivation indices are compared and the relation between the two indices are assessed. LLTI is added to the mortality multilevel model after age, sex, and deprivation have been controlled for, and vice versa with mortality being added to the LLTI model, to see if the unexplained variation can be reduced further.

\section{RESULTS}

\section{Relations between health outcomes and deprivation}

Figure 1 displays scatterplots illustrating the relations between the standardised health outcomes and the Townsend deprivation index in the different area types. Although all of the relations are positive, the strength varies substantially between the area types and health outcomes. The strong relation between LLTI and the Townsend deprivation index in urban areas $(r=0.72)$ becomes a lot weaker in the fringe $(r=0.27)$ and weaker still in rural areas $(r=0.18)$. A similar pattern also emerges from the relation between mortality and the Townsend index, with the strong relation in urban areas $(r=0.61)$ again becoming weaker in the fringe $(r=0.14)$ and rural areas $(r=0.22)$. In the urban and fringe areas the relation with deprivation is stronger for LLTI than for mortality, however there is little difference in the strength of these relations in rural areas.

Tables 1 and 3 display Poisson multilevel modelling results taking LLTI and mortality as the outcome variables and comparing the Townsend deprivation index, with customised deprivation profiles as predictors, after controlling for age and sex, separately for urban, rural fringe, and rural areas. For all areas the risk of having a LLTI is greater for men in all age groups. However, in the urban and fringe models interactions between age and sex are significant and indicate that this difference is attenuated with increasing age. The results of the relative risks for these interactions are shown in table 2 for LLTI.

Interactions between age and sex significantly improve all of the mortality models, with the risk of mortality being greater for men than women in all age groups, and this

Table 3 Fitted models $†$ for mortality comparing deprivation measures

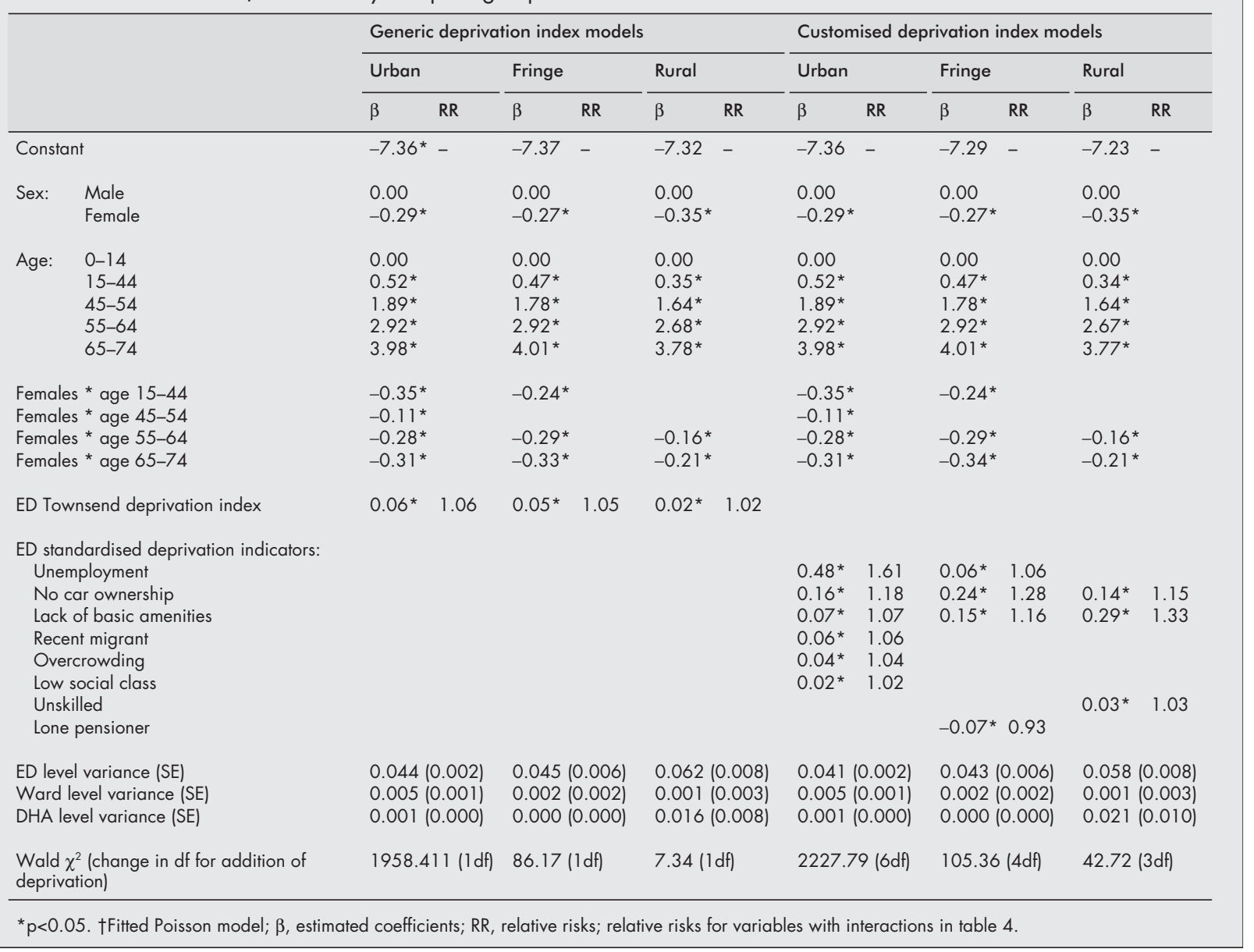


Table 4 Relative risks of mortality by age and sex for urban, fringe, and rural models

\begin{tabular}{|c|c|c|c|c|c|c|}
\hline & \multicolumn{2}{|l|}{ Urban } & \multicolumn{2}{|l|}{ Fringe } & \multicolumn{2}{|l|}{ Rural } \\
\hline & Males & Females & Males & Females & Males & Females \\
\hline $0-14$ & 1.00 & 0.75 & 1.00 & 0.76 & 1.00 & 0.71 \\
\hline $15-44$ & 1.68 & 0.89 & 1.60 & 0.96 & 1.41 & 1.00 \\
\hline $45-54$ & 6.65 & 4.45 & 5.91 & 4.50 & 5.16 & 3.64 \\
\hline $55-64$ & 18.50 & 10.51 & 18.49 & 10.51 & 14.50 & 8.74 \\
\hline $65-74$ & 53.73 & 29.49 & 55.15 & 30.02 & 43.34 & 24.71 \\
\hline
\end{tabular}
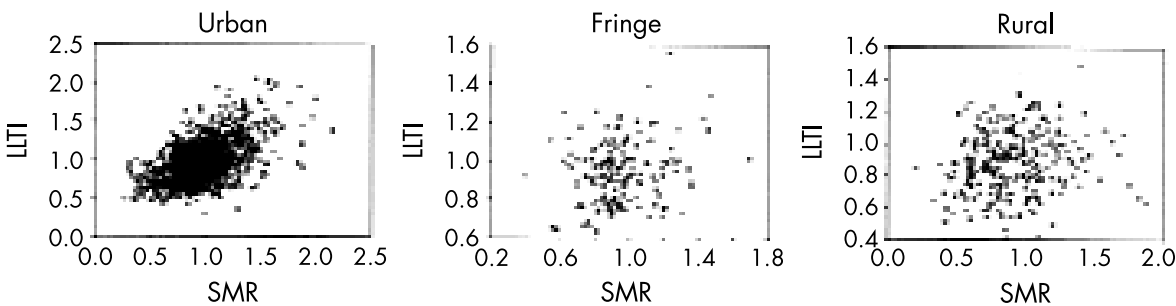

Figure 2 Scatterplots showing the relation between the standardised mortality ratios (0-64) and standardised LLTI ratios (0-64) at ward level by area type.

difference is accentuated with increasing age. The relative risk for these interactions are shown in table 4.

The addition of deprivation, whether the generic or customised measures, has a positive relation with both health outcomes and significantly reduces the unexplained variation in all area types. Once again for all area types and for both health outcomes, the replacement of the generic deprivation index with a customised deprivation profile is an improvement in further reducing the unexplained variation, especially at the ED level. This occurs at all three levels in the LLTI model, however, the reductions are only seen at the ED level in the mortality model. The remaining unexplained ED level variation in all three area types is far greater for mortality than morbidity.

\section{Relation between mortality and LLTI}

Figure 2 shows the relation between the standardised mortality and morbidity ratios for each area type. Mortality has a fairly strong relation with morbidity in urban areas $(r=0.55)$, but this is much weaker in the fringe $(r=0.21)$ and in rural areas $(r=0.16)$.

Figure $3 \mathrm{~A}$ illustrates the distribution of the urban, fringe, and rural areas, based on the ONS Ward Classification. Figure 3B displays the standardised LLTI residuals divided into quartiles, from a regression analysis on mortality. The positive values indicate areas where the LLTI is greater than expected given the mortality rate and vice versa for negative values. It reveals a distinct pattern of higher rates of LLTI than one would expect in the more rural parts of the south west.

Weak relations have been observed between mortality and morbidity at the small area level in figure 3 especially in the fringe and rural areas. Figure 4 examines the relation between the LLTI and mortality customised deprivation indices computed in the multilevel modelling. In contrast with the weak direct relations between mortality and morbidity there are very strong positive relations between the customised deprivation indices used to predict mortality and morbidity. This is especially so for the urban areas $(r=0.99)$ where the customised deprivation indices are practically interchangeable, and although weaker, the correlation coefficients are still strong in the fringe $(r=0.76)$ and rural areas $(r=0.74)$. The customised deprivation indices did not have such strong relations with the generic deprivation index. The relation between the LLTI deprivation index and the Townsend index was strong in urban areas $(r=0.84)$ but the difference was more visible in the fringe $(r=0.40)$ and in rural areas $(r=0.32)$. Similar patterns were seen in the relation between the mortality deprivation index and the Townsend index with a strong relation in urban areas $(r=0.87)$, and again becoming much weaker in the fringe $(r=0.31)$ and rural areas $(r=0.13)$.

Tables 1 and 3 show that although there are differences between the customised deprivation profiles in the selection of deprivation characteristics and in the estimated coefficients, similarities are apparent, namely within the same area type than within the same health outcome. The mortality models tend to have fewer significant deprivation indicators than in the morbidity models, but most of these variables also occur in the morbidity models for that area type.

The mortality model was tested with the addition of LLTI to see whether levels of morbidity could further explain the spatial variation in mortality after controlling for age, sex, and deprivation, and vice versa for the LLTI model. However, as the impact on all of the models was minimal the results are not shown. In the LLTI models, although mortality was significantly associated it failed to reduce the unexplained variation at any of the levels in any of the area types. In the mortality models LLTI was only significant in the urban model and once again it failed to reduce the unexplained variation.

\section{DISCUSSION}

LLTI, mortality, and deprivation are widely used to measure health care need, allocate health care resources, and within health research. However, the interrelations between these three variables have not previously been examined in detail at the small area level, and in particular whether the relations vary between urban and rural areas.

Firstly, we examined the relations between the health outcomes and deprivation. We have previously shown that there are strong positive relations between LLTI and deprivation in the urban areas, which become a lot weaker in the fringe and rural areas. This study shows the same relation for mortality, suggesting that generic deprivation indices are poor explanatory variables of these health outcomes in rural locations, in contrast with their established effectiveness in urban areas. A possible explanation could be that the pattern of disease varies between urban and rural areas, and that those seen in rural 

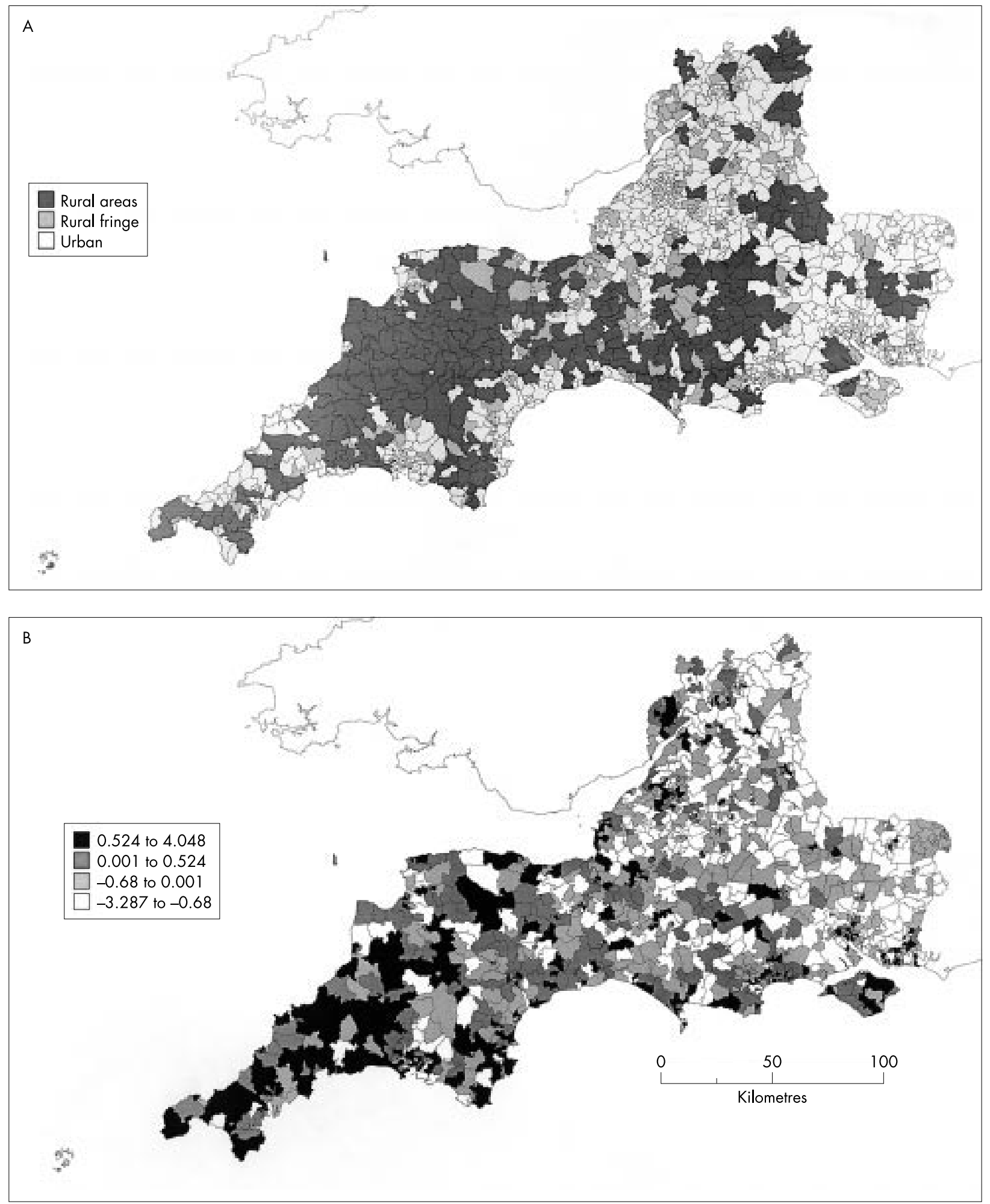

Figure 3 (A) The ONS ward classification (groups). (B) Standardised LLTI residuals from regression on mortality (0-64).

areas have weaker relations with deprivation. There is substantial variation in the degree to which various morbidities are related to socioeconomic variables $(r=0.2$ to $r=0.8){ }^{26}$ For example, suicide ${ }^{27-30}$ and road traffic accidents ${ }^{3132}$ have been highlighted as having higher rates in rural areas. However, these are not main causes of death in rural areas, the predominant cause being coronary heart disease as in urban areas. Moreover rural general practitioners have argued that poverty and poor health are associated in rural areas just as they are in urban areas ${ }^{33}$ suggesting that the lack of a relation is partly attributable to the census based generic deprivation indices not detecting rural deprivation adequately. ${ }^{13}$

The relations with deprivation are stronger for LLTI than mortality suggesting that morbidity is more sensitive than mortality to variations in social deprivation. This has been found in other studies at both the ward and local authority levels. ${ }^{17}{ }^{34} 35 \mathrm{It}$ has been suggested that this is attributable to social inequality having a greater impact on morbidity than mortality. ${ }^{36}$ 


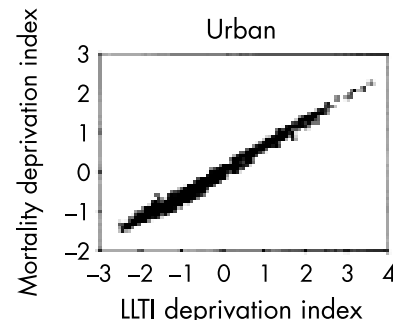

LLTI deprivation index

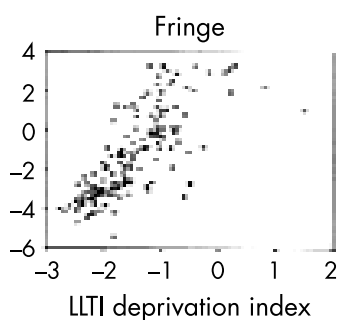

LLTI deprivation index

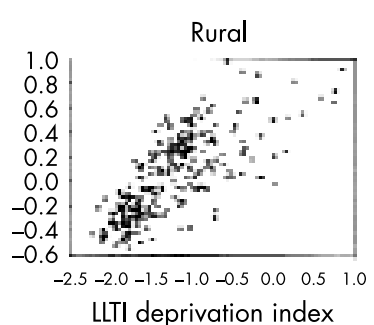

Figure 4 Scatterplots showing the relation between the deprivation indices at ward level by area type.

\section{Key points}

- The relations between deprivation, and the two health outcomes are stronger in urban than rural areas.

- These relations are stronger when the customised indices replace the generic indices.

- The relations between mortality and morbidity do not seem to be as strong at the small area level compared with findings by others using larger areal units.

- The relation between mortality and morbidity is weaker in rural areas, where levels of LLTI tend to be higher than expected from the levels of mortality. However, when the relations between the two health based customised indices are examined the relations are very strong in all areas.

- The distinct theme of stronger relations in urban areas between these three different proxies of need suggests that the choice of indicator will make little difference in urban areas, however it will have a marked impact on resource allocation in rural areas.

The addition of deprivation, whether generic or customised indices are used, to models controlling for just age and sex significantly reduces the unexplained variation in both mortality and morbidity in all area types. A comparison between the generic and customised indices shows that the latter reduce the unexplained variation more for both health outcomes in all area types, but especially for LLTI in rural areas.

The relation between mortality and morbidity mirrors closely that found for the health outcomes and deprivation. The relations are far stronger in urban than fringe and rural areas. Mortality data have in the past been used as a suitable proxy for morbidity; for example SMR was included in RAWP allocation formula. ${ }^{18}$ The LLTI measure in the 1991 census has allowed the strength of the mortality/morbidity relation, to be tested, although to date this has only been performed at higher aggregations and without distinguishing between area types. At the local authority level variations in morbidity were found to be associated with over $60 \%$ of the variation in all cause mortality ${ }^{17}$ and a strong correlation $(r=0.8)$ was also found by Charlton et al. ${ }^{16}$ We have found that this relation is much weaker at lower levels of aggregation. ${ }^{3}$ In the multilevel modelling, variations in the health outcomes remain after controlling for age, sex, and deprivation, however the addition LLTI to the mortality model and vice versa has a minimal impact.

The use of mortality as a proxy for morbidity assumes the relation between the two measures to be close and consistent across areas. However, this rests on the implicit assumption that LLTIs, which are not life threatening, should still closely relate to all cause mortality. Mortality reflects the fatal consequences of both chronic diseases, such as coronary heart disease, as well as acute events such as severe accidents. Morbidity not only reflects the non-fatal consequences of such diseases/events, for example angina or disability after a severe accident, but also reflects the disability arising from non-fatal events such as osteoarthritis of the hip or knee.

Rural areas in particular seem to have higher levels of LLTI than one would expect from their mortality levels. This reflects previous findings at the local authority level, where higher illness levels than expected from the mortality levels were found in Wales, South West, and East Anglia, ${ }^{17}$ all areas with major concentrations of extreme rurality. ${ }^{38}$ A study in Wales also found a higher prevalence of LLTI than expected. ${ }^{39}$ This suggests that LLTI may be a problem in rural areas but not associated strongly with higher mortality rates. As LLTI is a self reported measure ${ }^{13}$ it is unclear how much the results reflect an actual higher prevalence of illness or a measurement error. Cultural factors may affect responses to this question or the same level of disability may produce a greater handicap in rural areas because of increased accessibility problems. This would still have important implications for trying to achieve equity of access to health care and public services. Alternatively, it could be that isolated rural areas truly have high levels of LLTI, for example illnesses such as arthritis, which are not fatal but are limiting. This requires further research.

The relations between the LLTI and mortality customised deprivation indices are very strong. This is the case in all of the area types, but especially in urban areas $(r=0.99)$ where the indices are, to all practical extents, interchangeable. The deprivation characteristics included in the customised profiles vary between the area types and health outcomes, however, greater similarity is seen between the health outcomes within the same area types than between the urban and rural areas. This emphasises the importance of modelling urban and rural areas separately. The geographical variations in LLTI and mortality at the small area may be very different but both are related to area level socioeconomic factors. The relations between the Townsend deprivation index and the customised deprivation indices were fairly strong in urban areas, although, the relations in all area types were weaker than between the two customised indices, especially in the fringe and rural areas. This suggests that health related deprivation is better defined using customised deprivation indices than generic deprivation indices, especially in the rural locations.

While deprivation indices, mortality and morbidity data could be used interchangeably as proxies of health care need in urban areas, the weaker relations between them in rural areas could have important implications for health needs assessment and resource allocation. Rural areas may lose out in resource allocation not only using generic indices as these are urban biased ${ }^{13}{ }^{14}$ but also using mortality as this study indicates that in rural areas LLTI seems to be higher than expected from the mortality rates. A more accurate basis for assessing health care need especially in rural areas might be to combine measures of mortality, morbidity, and deprivation.

There are a number of important limitations to this study. The study covers only one region and the findings need replicating in other areas. The self reported nature of LLTI has been discussed in a previous paper. ${ }^{13}$ One prevailing issue is the small number problem arising from the rarity of health events. This is more of an issue for mortality, which led to the aggregation of all deaths between 1991-1996, and the use of a wider age range. However, the mortality rate was still far smaller than for LLTI, especially in rural areas. This may have an impact on the weaker relation between deprivation and mortality as the number of deaths may be too small for mortality to form strong relations with any factors, as the difference of 
just one or two deaths will produce variation. The small number of health events at the small area level, especially in rural areas, indicates that perhaps an alternative proxy of health care need should be used in favour of or in combination with the SMR and LLTI ratios to allocate resources at the small area level.

Further research is needed that focuses on specific causes of mortality and morbidity. It would be useful to identify which causes prevail in urban and rural areas, and how the relations between these variables and deprivation vary between the area types. As there are problems of self reporting associated with the LLTI measure ${ }^{13}$ and the fact that it does not distinguish between different conditions it would be useful to have more comparisons between the LLTI measure and other measures of morbidity. ${ }^{40}$ The analysis of LLTI is important as at present these are the only nationally available data on morbidity at the small area level, it is used in resource allocation, ${ }^{41}$ and it is included in the 2001 census. Nationally representative surveys are needed that record self reported health problems and disability similar to the Health Survey for England and the OPCS Disability Survey can be broken down at the small area level. More specific surveys and qualitative research should explore the levels of ill health and their burden in rural areas, particularly in relation to access to health services. Further research into the relationship between health and deprivation is required to develop measures of health care need in rural areas, possibly looking at alternatives to census data.

In conclusion, there are important areal differences in relations between mortality, morbidity, and deprivation. In rural areas the interrelations are all weak, the customised deprivation indices are an improvement over the generic and LLTI is greater than would be expected from the levels of mortality. Therefore the use of mortality and generic deprivation indices as proxies for health care need are likely to disadvantage rural areas.

\section{Authors' affiliations}

S Barnett, I Diamond, Department of Social Statistics, University of Southampton, Southampton, UK

P Roderick, H Wrigley, Health Care Research Unit, University of

Southampton, Southampton General Hospital, Southampton

D Martin, Department of Geography, University of Southampton

Funding: Sarah Barnett was supported by Medical Research Council studentship G610/47, Hannah Wrigley by a South West Regional Research and Development grant.

Conflicts of interest: none.

\section{REFERENCES}

1 Mays N, Bevan G. Resource allocation in the Health Service-a review of the methods of the Resource Allocation Working Party.London: Bedford Square Press, 1977.

2 Forster D. Mortality, morbidity and resource allocation Lancet 1997;i:997-8.

3 Snaith $\mathbf{A H}$. Sub-regional resource allocations in the National Health Service. J Epidemiol Community Health 1988;32:16-21.

4 Brennan $M$, Clare P. The relationship between mortality and two indicators of morbidity. J Epidemiol Community Health 1980;34:134.

5 Mays N. NHS resource allocation after the 1989 white paper: a critique of the research for the RAWP review. Community Medicine 1989;11:173-86.

6 Carstairs V, Morris R. Deprivation: explaining differences in mortality between Scotland, England and Wales. BM 1989;299:886-9.

7 Smith P, Sheldon T, Carr-Hill R, et al. Allocating resources to health authorities: results and policy implications of small area analysis of use of inpatient services. BM 1994;309:1050-4.
8 Haynes R, Bentham G, Lovett A, et al. Effect of labour market conditions on reporting of limiting long term illness and permanent sickness in England and Wales. J Epidemiol Community Health 1997;51:283-8.

9 Townsend P, Davidson N, Whitehead M. The Black Report and The Health Divide. Harmondsworth: Penguin Books, 1988.

9a Cairstairs V, Morris R. Deprivation: explaining differences in mortality between Scotland and England and Wales. BM 1989;299:886-9.

10 Jarman B. Identification of underprivileged areas. BM 1983;286:1705-9.

11 Townsend P, Phillimore P, Beattie A. Health and deprivation: inequality and the north. London: Croom Helm, 1988.

12 Department of the Environment. Index of local conditions: an analysis based on 1991 census data. London: HMSO, 1995.

13 Barnett S, Roderick P, Martin D, et al. A multilevel analysis of the effects of rurality and social deprivation on premature limiting long term illness. J Epidemiol Community Health 2001;55:44-51.

14 Martin D, Brigham P, Roderick P, et al. The misrepresentation of rural deprivation, Environment and Planning A 2000;32:735-51.

15 Payne J N, Coy J, Patterson S, et al. Is use of hospital services a proxy for morbidity? A small area comparison of the prevalence of arthritis, depression, dyspepsia, obesity, and respiratory disease with inpatient admission rates for these disorders in England. J Epidemiol Community Health 1994;48:74-8

16 Charlton J, Wallace M, White I. Long-term illness: results from the 1991 census. Population Trends 1994;75:18-25.

17 Bentham G, Eimermann J, Haynes R, et al. Limiting long term illness and its associations with mortality and indicators of social deprivation. $J$ Epidemiol Community Health 1995;49:S57-64.

18 Morris R, Carstairs V. Which deprivation-a comparison of selected deprivation indexes. J Public Health Medicine 1991;13:318-26.

19 Diggle P, Elliot P. Disease risk near point sources: statistical issues for analyses using individual or spatially aggregated data. J Epidemiol Community Health 1995;49:20-7.

20 Diamond I, Clements S, Stone N, et al. Spatial variation in teenage conceptions in South West England. Journal of the Royal Statistical Society Series A 1999; 162:273-89.

21 Goldstein H, Rasbash J, Plewis I, et al. A user's guide to M/wiN. London: Institute of Education, University of London, 1998.

22 Langford IH, Bentham G. Regional variations in mortality rates in England and Wales: an analysis using multi-level modelling. Soc Sci Med 1996;42:897-908.

23 Hox JJ. Applied multilevel analysis, Amsterdam: TT-Publications, 1995.

24 Kreft I. Introducing multilevel modelling. London: Sage, 1998

25 Goldstein H. Multilevel statistical models. 2nd edn. London: Edward Arnold, 1995.

26 Saul C, Payne N. How does the prevalence of specific morbidities compare with measures of socio-economic status at small area level?. J Public Health Medicine 1999;21:340-7.

27 Crombie IK. Suicide among men in the highlands of Scotland. BM $1991 ; 302: 761-2$.

28 Charlton J. Trends and patterns in suicide in England and Wales. Int J Epidemiol 1995;24:45-52.

29 Saunderson TR, Langford $\mathrm{IH}$. A study of the distribution of suicide rates in England and Wales 1989-92 using Empirical Bayes Estimates. Soc Sci Med 1996;43:489-502

30 Law MR, Morris JK. Why is mortality higher in poorer areas and in more northern areas of England and Wales. J Epidemiol Community Health 1998:52:344-52.

31 Bentham G. Proximity to hospital and mortality from motor vehicle traffic accidents. Soc Sci Med 1986;23:1021-6.

32 Daly K E, Thomas PRS. Trauma deaths in the South West Thames Region. British Journal of Accident Surgery 1992;23:393-6.

33 Cox J. Poverty in rural areas: is more hidden but no less real than in urban areas. BM 1998;316:722.

34 Haynes R, Gale S. Deprivation and poor health in rural areas: inequalities hidden by averages. Health and Place 2000;6:275-85.

35 Huff N, Macleod C, Ebdon D, et al. Inequalities in mortality and illness in Trent NHS Region. J Public Health Med 1999;21:81-7.

36 Davey Smith G. Income inequality and mortality: why are they related? BM 1995;312: 987-8.

37 Palmer S, West $P$, Patrick $D$, et al. Mortality indices in resource allocation. Community Medicine 1979;1:275-81.

38 Cloke P, Edwards G. Rurality in England and Wales 1981: a replication of the 1971 index. Regional Studies 1986,20:289-306.

39 Senior ML, Williams HCWL, Higgs G. Spatial and temporal variation of mortality and deprivation 2: statistical modelling. Environment and Planning A 1998:30:1815-34.

40 Jordan K, Nio Ong B, Croft P. Researching limiting long term illness. Soc Sci Med 2000;50:397-405.

41 Department of Health. HCHS revenue resource allocation to health authorities: weighted capitation formulas. Leeds: NHS Executive, 1997. 